\title{
Developing Communication Skills through Raising Intercultural Competence in EFL Classroom
}

\author{
Vipin Sharma \\ English Language Institute, Jazan University, Jazan, Saudi Arabia \\ *Corresponding author. E-mail :vipinaravali@gmail.com \\ https://doi.org/10.12982/CMUJASR.2020.005
}

\begin{abstract}
This article discusses the teaching of intercultural and transcultural awareness together with language learning in foreign language contexts. Ensuing a brief discussion of what language, culture and its forms mean, we illustrate the relationship between intercultural and transcultural competence, and the development of communication skills in the foreign language framework for teaching EFL (English as Foreign Language) students. The author draws attention to the importance of developing students' intercultural research abilities utilizing the transcultural communication competence notion. We show how intercultural orientations and transcultural communication competence affect the students' framework and their career dimensions. The author illuminates the activities and approaches that develop communication skills. The article concludes with an underscoring of the critical challenges that teachers encounter and their potential solutions.
\end{abstract}

Keywords: Intercultural communication, Transcultural awareness, Social identity, Student attitudes, Cross cultural, EFL classrooms, diversity

\section{INTRODUCTION}

Students rely greatly on their linguistic skills to articulate their ideas, thoughts and opinion. This is essential for them to communicate with friends and colleagues from both national and international realms. We know that the message and the process are of paramount importance for students when they communicate at different settings as follows: study tours, online discussion forums, social media interaction, email correspondences, visiting overseas tourist attractions, and seeking employment. Meticulous attention is needed to ensure that the communication process is completed without any distortion, delusion or misinterpretation. Multiple innovations and massive proliferation of knowledge in various disciplines and domains across the world have made communication more intricate; thus, communication competence has become a prerequisite for effective communication. The privatization, liberalization, globalization and technology advancement in business and other areas have transformed language and society, and consequently, such transformation has impacted people in their perceptions, attitudes, and behaviors across different regions, cultures, traditions and societies. Furstenberg (2010) opined that culture provides the factual process and shapes human behavior 
and interaction in specific situations. Keeping abreast of these alterations conceptually and perceptively can create a bridging space for language learners as they seek intercultural and transcultural awareness for effective communication. Furthermore, the opening up of boundaries can enhance greater interaction between people from different regions and cultures. In so doing, with basic knowledge about targeted culture, people could enjoy significant and expressive communication.

In the case of Saudi learners, they have experienced interaction with people from other cultural and social backgrounds. For the Saudi EFL learners to have effective communication with people from targeted cultures, these learners are in need of reliable cultural knowledge from the European, Western, Asian and other geographical contexts. The author affirms that operationalizing the concept of language and culture, and its related aspects encapsulating both intercultural and transcultural communication can build a solid foundation for the structural framework in designing the textbook content and other activities in EFL classrooms. This article is guided by Chlopek's (2008) work, and it reviews various inter-andtranscultural studies in the EFL contexts that explicate culturally-oriented students through an intercultural communicative competence model. This article also seeks to underscore the importance of developing students' intercultural research skills utilizing the transcultural communication competence notion and how these concepts affect the students' career paths. Finally, this article attempts to mitigate a few critical challenges EFL teachers face by suggesting potential solutions that may be implemented in the process of developing the students' communication skills in various EFL cultural contexts.

\section{CULTURE AND LANGUAGE}

Culture and language are two sides of a coin. Both are interrelated, interdependent, inter-reliant and always move together in any form of communication. Hornby (2010) defined culture as the customs and beliefs, art, way of life and social organization of a particular country or group. The word "culture" is derived from a French term, which is taken from the Latin word "colere" that means "disposed to the earth and develop," or "cultivation and support." We may see culture as the features and awareness of a specific cluster of people, including language, social customs, traditions, behaviors, religion, food, arts, music and others. Similarly, language is a system of spoken sounds or written symbols that people use to express themselves during communication in a specific cultural setting or social group. Both are needed to develop mutual rapport among people or social groups in different specific cultures in which the participants are continually establishing the societal, moral, cultural, and religious values of the contacting cultures. Kaikkonen (1994) upheld the point stating that culture is a mutual agreement between the members of a certain society about the values, rules, role expectations, and meanings, which direct the behavior of the members. Therefore, it's pertinent to include cultural factors in language teaching. The absence of target culture awareness may jeopardize the significance of effective communication. Chlopek (2008) asserted that communication lacking appropriate cultural content often results in humorous incidents, or worse, it is the source of serious miscommunication and misunderstanding. The current scenarios, therefore, prompt academicians, scholars 
and students to gain knowledge of the social, theoretical and cultural aspects of the target culture.

The inclusion of culture concept within the curriculum has gained momentum in the twentieth century and many researchers have reflected on the importance of teaching culture while teaching foreign or second languages (Byram \& Kramsch, 2008; Dai, 2011: Farooq et.al, 2018). Building relationships, cultivating positive attitudes and developing desired behaviors are further supported by Nieto (2010:136) who argued that culture includes "a shared world-view, common history, geographic location, language, social class, and religion." Emphasizing its significance in EFL-teaching, Farroq et.al. (2018) argued that it is a teacher's duty to integrate culture in the language class by keeping in view the impact of globalization on various aspects of the society while raising awareness of the various cultures in the world. Furthermore, Seriwatana and Charoensukmongkol (2021) worked on the contribution of cultural intelligence (CQ) to team relationship conflict and team trust, and concluded that cultural intelligence (CQ) has been negatively related with team relationship conflict while being positively related with team trust.

Keeping the concept alive and operative, we need to enlighten and explain the intercultural and transcultural concepts needed for a better understanding of the role of culture in EFL contexts.

\section{INTERCULTURAL, TRANSCULTURAL AND TRANSACTIONAL CULTURE}

Adding on to the preceding discussion on language and culture, we need to understand the different terms related to culture that vary in meaning. Such an understanding will generate better perspectives when interacting with people from other cultures. Intercultural calls on groups with strong attraction, deep understanding and proper respect for all cultures, and the communication, primarily will focus on the conjoint interchange of ideas, opinions, thoughts, values, beliefs, moral and cultural norms to develop resilient affiliations. People in an intercultural society will seek to live harmoniously through sharing, motivating and supporting one another in all trying situations. Besides, the term "multicultural" describes a culture that consists of many different racial, social and ethnic groups. Many nations have multicultural societies where people usually interface with each other. In addition, another descriptive form of culture is known as "cross-cultural." Crosscultural society accentuates the features of different cultures that are included in communication for better comprehensibility and knowledge transfer. In such a setting, the participants seek to bring the desired social and behavioral change in individuals while reflecting how other cultures could be compared with or contrasted to one prevailing culture acting as a standard base. Intercultural awareness becomes indispensable when people of different cultures communicate with one another; therefore, it needs the appreciation of the nuances of different cultures, including one's own, to make the communication worthy, meaningful, accurate and complete. A better knowledge and deeper understanding of different cultures will help people to go beyond casual interactions to achieve formal communication at professional settings. This form is not confined within any 
personal space, but it emphasizes on building transactional relationships to accomplish business or commercial activities. Similarly, Abuelma'atti (2005) saw globalization through an economic angle. In order to enhance business for profit, the Western governments have sought to promote certain cultural and political agenda to achieve economic objective and interests. Within the same field, Risager (1998) advocated these three approaches: intercultural or multicultural, transcultural, and foreign cultural where each produces a different aspect and assumption. Adding to the preceding definitions, the following contributions are made: (a) the intercultural approach proposing a sizeable element for comparison; (b) the transcultural approach contemplating the foreign language as an international language; and (c) the foreign cultural approach keeping the target culture as the central point. Thus, these given explanations have augmented the necessity for students to adopt cultural awareness in their acquisition of linguistic skills so that they could interact with people of other cultures effectively.

\section{INTERCULTURAL AND TRANSCULTURAL IN TRANSACTIONAL CULTURAL COMPETENCE}

Gaining an adequate knowledge of nuances and efficacy of both intercultural and transcultural communication in the global arena builds a solid foundation to incorporate both concepts in teaching English as a foreign language. Canagarajah (2005), while exploring the global uses of English and English teaching, opined cultures as hybridized, diffused and de-territorialized with constant movement between different local and global communities. Furthering the mobility, Pennycook (2007) stated that the ways in which cultural forms move and change are reused to fashion new identities in diverse contexts. Likewise, Risager (2007) offered a theoretically-justified alternative to the national paradigm and deliberated on the transnational flows of linguistic and cultural practices comprising a divergent approach to understanding their relationships in language teaching. The inclusion of cultural awareness in the EFL classroom may facilitate students to develop a better understanding of ethnographic groups (people and cultures with their customs, habits, behavior, and mutual differences) and sociolinguistic aspects in varied cultural contexts. Therefore, we may classify language and culture as "body and soul" both in formal and informal interactions, which are explained by sociocultural theories of language learning as a socially-situated activity (Lantolf and Thorne, 2006). To Risager (2007), such a classification can be interpreted as a "marriage of language and culture." Besides, scholars (Byram, 2008, Kramsch, 2009) have also argued that effective approaches in language teaching should be included in classroom teaching so that intercultural competence in language education can be embraced in an orderly and organized way. By gaining sound knowledge of intercultural and transcultural aspects, the learners can develop transactional cultural competence, which enables them to interact and negotiate effectively with professionals across cultures possessing varied beliefs and agendas. Improving cultural competence in the classroom prepare learners to interact with others freely through face-to-face meetings, social media platforms, phone calls or email correspondences. In so doing, their performance and productivity will be 
significantly elevated, albeit requiring patience, resilience, time and a commitment to language education.

\section{IMPORTANCE OF DEVELOPING STUDENT'S INTERCULTURAL RESEARCH UTILIZING THE TRANSCULTURAL COMMUNICATION COMPETENCE NOTION}

We do believe that teaching and learning a foreign language cannot be reduced to the direct teaching of linguistic skills like phonology, morphology, vocabulary, and syntax. Learning a language well usually requires knowing something about the culture of that language (Chlopek, 2008). The EFL learners, therefore, cannot be complacent with gaining proficiency in linguistic skills by ignoring the cultural understanding of the target language. This is especially crucial in a global culture where adaptability, flexibility and resilience to communicate with people across nations are indispensable. Continuous interaction in professional settings needs intercultural competence where risky business communications are transformed into fruitful outcomes while setting the tone for future transactions. Dealing with people of different cultures is an integral part of life routines, and it goes beyond personal aspects of interpersonal communications. People have different hobbies and customs because of their cultural backgrounds. The diverse habits and customs may cause problems in people's intercultural communication, especially when this intercultural communication takes place between people with distinct cultural backgrounds. Moreover, each culture has its own unique features, identity, customs, beliefs and etiquettes, which have a profound effect on an individual's intercultural communication. Furthermore, different cultural backgrounds will lead to different results in intercultural communication. The learners have to acquire adequate knowledge of the foreign culture and language. For this, gaining insights of the target culture and its features are equally essential in language learning. In the Saudi context, the learners have a rich culture, and with an insight of the target culture, they become confident, motivated and autonomous. Integrating knowledge of different cultural awareness widens their horizon in developing intercultural communication competence. As they cultivate transcultural competence, they will receive both intrinsic and extrinsic values including social, psychological, political, economic and other benefits. The inculcation of cultural understanding will also keep the learners energized and motivated. As a result, they will develop greater learning abilities with resilience and tolerance while attracting opportunities to create, cooperate and collaborate with people of different cultures. Eventually, they will experience better health, life, social security and safety of self and societies at large, which are essential ingredients for the students' careers in 21st-century.

\section{INTERCULTURAL AND TRANSCULTURAL COMMUNICATION COMPETENCE AFFECT STUDENTS' CAREER}

Considering the aforesaid perspective, the explanation has provoked a transformed interest in intercultural communication competence in language learning among students to take on future interaction in the global arena. Chlopek 
(2008) declared that in addition to grammatical competence, a culturally competent learner must possess sociolinguistic competence, pragmatic competence, sociocultural knowledge, and intercultural awareness. Also, increasing pressure from teachers, peers, parents and society force students to not only gain advance language learning and use, but it also drives them to consider the target culture's social, political, and multilingual players for career enrichment. Integrating knowledge and understanding of both cultures and foreign language proficiency will enhance the user's capability, aptitude, cognitive ability, ethical wisdom, body language, courtesy, social interaction, discourse management, self-esteem, and communication style to set directions for building strong relationships and attaining desired objectives. Besides, intercultural communication competence also develops flexibility, inter-societal knowledge, amalgamation and perception, constructive and effective communication, and awareness of different cultures. Then, the application of theoretical knowledge gained by the students in developing intercultural communicative competence and linguistic behavior in commercial activities, economic production and business transactions may assist them in excelling their work in the specific domains. It will also develop a theoretical basis for future foreign language learners to gain advantage in the competitive world.

\section{ACTIVITIES AND APPROACH THAT DEVELOP COMMUNICATION SKILLS}

The EFL learners, in the Saudi context, are monolingual candidates who are situated in homogeneous classrooms with no or little exposure to English as a target language and culture. With no multicultural education in the school curricula, they have limited multi-or-target cultural knowledge and language proficiency. Decisively, their aim for language acquisition is not limited to studying abroad. On the contrary, it is to equip them to communicate with people from different cultures and languages through English, which is the common accepted language known globally as "English as International Language" (EIL) or "English as Lingua Franca" (ELF). The process involves both teachers and students where the teacher becomes the dominant player before moving to the classroom with some innovative and creative intercultural awareness activities. Therefore, preparing activities based on intercultural awareness is a daunting task for teachers if they do not possess adequate knowledge about both the native and the target cultures. With better knowledge and understanding, teachers will find it easier to plan activities based on the textbook content that invite, engage and involve students in participating in the EFL classroom activities. Increasingly, the students' interest and participation create a conducive and healthy learning classroom environment leaving no room for any confusion, misperception and miscommunication. As an extension to the activities focusing on target culture awareness, Kramsch (1993) asserted that culture is always in the background, right from day one, ready to unsettle the good language learners when they expect it least, making evident the limitations of their hard-won communicative competence, challenging their ability to make sense of the world around them. Henceforth, the EFL teacher should be well aware of the native and target cultures to avoid any chaos, confusion and conflict. The teacher should make 
sure that the emphasis on the target culture should not dominate or overshadow the native culture.

Chlopek (2008) suggested three general stages to be used while implementing the intercultural approach in an EFL classroom. He proposes:

Beginning with the students' own cultural background and the cultures that the students have direct contact with, the teacher may then expand it to all world cultures. Young teachers may make appropriate adjustments before applying these ideas. For example, teachers can conduct parts of the activities in the students' native language. Secondly, they can use introductory activities, which pre-teach relevant vocabulary words or grammar structures while introducing key concepts. Thirdly, they simplify texts or design activities in such a way that students can cope with a more difficult text. Finally, they can adapt activities in agreement with the students' stage of cognitive development (Chlopek, 2008).

The aforementioned actions require the teachers' attention and their willingness to plan, prepare and execute intercultural awareness activities based on the approved curriculum in the EFL classroom. The department may conduct some workshops or seminars on intercultural training and prepare some formal or informal guidelines before the teachers move into the classroom. The teachers' rapport and social behavior may motivate students to partake, cooperate, and collaborate with their peers to develop intercultural awareness. In the monocultural and monolingual Saudi context, the teacher with his expertise and experience should customize language learning activities that first connect with the students' cultural background, Subsequently, the teacher should then move on to the next nearest familiar culture before finally taking it off to other cultures, which, in fact, can constitute multiple challenges.

\section{CRITICAL CHALLENGES EFL TEACHERS ENCOUNTER AND POTENTIAL SOLUTIONS}

The EFL teacher plans and prepares activities that conform to the prevailing norms, curriculum and contexts. However, it has been observed that the textbook pedagogy includes recommendations of many foreign cultural components. Thus, careful attention and evaluation to study the effects of the teaching materials on the particular concerned learners (Tomlinson, et al. 2001). The curriculum committee may design, prepare, formulate and propose course materials to include some alterations with appropriate materials that serve both purposes in developing intercultural awareness and its application in real-life situations. Pertaining to using the updated teaching tools, Nault (2006) stated that the ELT specialists must take care in the selections of linguistic and cultural aspects in their texts to upkeep the sensitivity of the materials so as to meet the desired objectives needed in shaping the academic as well as the intellectual growth of the learners in the EFL context. Furthermore, on studying the effects of cultural aspects of British ELT textbooks to know the content, range, and role of the target culture in ELT, Gray (2006) who taught in Barcelona, found that the teachers have considered English as a lingua franca, but without any long-term cultural ambition, they have agreed to exclude all 
irrelevant contents from the textbooks. Similarly, Al Houssawi (2010) carried out a study in the Saudi context on the perceptions of English language teachers of a western textbook entitled North Star, and he found that the subjects of the study had a negative perception of the cultural models and traditions provided by North Star course book as it overlooked local culture and tradition.

Therefore, the multiple challenges have exacerbated the situation for the teachers, but an abrupt change in textbooks in the mid-semester may not be feasible. The teachers have incredible talents and immense potential to plan and prepare authentic activities that suit their students' tastes and preferences. The students will be engaged to partake in the activities at the individual, pair, peer group, and other levels. As a result, their morale and motivation shall increase. Timely guidance, support, and making the students aware of the vitality of intercultural awareness and transcultural competence will motivate them to take an interest that may subsequently develop their productive (writing and speaking) and receptive skills (reading and listening). Topics that aligned native culture and traditions to an international perspective will eventually make the students more aware of English as the lingua franca or the international language of communication, which can be correlated with their career goals and objectives.

\section{CONCLUSION}

This article aims at developing intercultural and transcultural awareness in learners together with language learning in the foreign language contexts. The author draws attention to the relationship between language and culture, forms of culture, and the importance of developing students' intercultural research utilizing the inter-or-transcultural communication competence notion, and how it affects the students' framework and their career dimensions. The aforesaid explanation on the vitality of intercultural awareness to EFL learners and its applications in transactional context is indeed productive and effective in building confidence, selfsustained attitude, and social relationships with people of different cultures. At the outset, it seems quite easy, but adopting the intercultural approach in preparing and executing activities in the EFL classroom is demanding, stimulating, and challenging for both teachers and students. It is a dynamic but a slow performing process where the students' native cultures, beliefs, traditions, values and other aspects are respected, and all stakeholders are eager to move along to gain intercultural communicative competence at an acceptable pace. Therefore, the EFL teacher should revisit, revise, evaluate, modify or redesign the existing curriculum so as to integrate both the target and the native cultures. Such integration incorporates the students' local and global needs while adopting a cautious approach through the use of the teacher's full wisdom, intellect, and experience in executing the intercultural and transcultural approach to avoid any confrontation. In the 21st-century, learners are required to gain not only linguistic skills, but they are to develop inter-ormulticultural communication competence to become an intercultural speaker, which needs a more perceptible and reasonable sketch of language use. Therefore, we call for a concrete and multicultural theoretical basis for understanding English as a foreign language, which further integrates itself with the social, psychological, cognitive, social, lexicon, and textual orientations to intercultural language 
acquisition. This study further opens avenues to explore more in other linguistic and cultural contexts that can provide a systematic intercultural language learning platform for the education of a new generation that needs to be more resilient, flexible, tolerant, open-minded, and respectful towards other world cultures in the future.

\section{REFERENCES}

Abuelma'ati, Z. (2005). Translation and cultural representation: Globalization of texts, localizing cultures. Unpublished Ph.D thesis. University of Salford. Salford: UK.

Al-Houssawi, H. (2010). The non-native English teachers' perceptions about the presented cultural values and traditions in North Star English Textbook in Saudi Arabia: Critical Issues in TESOL. Unpublished Ed.D thesis. University of Exeter.

Baker, W. (2016). Culture and language in intercultural communication, English as a lingua franca and English language teaching: points of convergence and conflict. In P. Holmes \& F. Dervin (Eds.), The cultural and intercultural dimensions of English as a lingua franca (pp. 70-89). Bristol: Multilingual Matters.

Byram, M. (2008). From foreign language education to education for intercultural citizenship: essays and reflections. Clevedon: Multilingual Matters Ltd.

Canagarajah, A. S. (Ed.). (2005). Reclaiming the local in language policy and practice. Mahwah, N.J.; London: L. Erlbaum Associates.

Chlopek, Z. (2008). The Intercultural Approach to EFL Teaching and Learning. English Language Forum, Vol.4, pp. 10-19.

Dai, L. (2011). Practical techniques for culture-based language teaching in the EFL Classroom. Journal of Language Teaching and Research, 2(5), 1031-1036. https:// doi.org/10.4304/jltr.2.5.1031-1036

Farooq, M.U., Soomro, A.F., Umer, M. (2018). English Language Teaching and Cultural Implications in Saudi Arabia. International Journal of English Linguistics; Vol. 8(3), pp. 177-185.

Furstenberg, G. (2010). Making culture the core of the class: Can it be done? The Modern Language Journal, 94(2), 329-332. https://doi.org/10.1111/j.15404781.2010.01027.x

Gray, J. (2006). A study of cultural content in the British ELT global coursebook: A cultural studies approach. Unpublished Ph.D thesis. Institute of Education, University of London.

Hornby, A.S. (2010). Oxford Advanced Learner's Dictionary. Oxford. Oxford University Press

Kaikkonen, P. (1994). Kulttuuri ja vieraan kielen oppiminen. Helsinki: WSOY.

Kramsch, C. (1993). Context and culture in language teaching. Oxford: Oxford University Press

Kramsch, C. (2009a). Third culture and language education. In V. Cook \& L. Wei Eds.), Contemporary applied linguistics (pp. 233-254). London: Continuum.

Kramsch, C. (2001). Language and Culture. Oxford: Oxford University Press.

Kramsch, C. (2010). The symbolic dimensions of the intercultural. Language Teaching, $1-14$.

Lantolf, J. and Thorne, S. (2006). Sociocultural Theory and Genesis of Second Language Development. Oxford: Oxford University Press. 
Nault, D. (2006). Going Global: Rethinking Culture Context in ELT Contexts. Language, Culture and Curriculum, 19(3), 314-328.

Nieto, S. (2009). Language, Culture and Teaching: Critical Perspectives (second edition). New York: Routledge.

Rathje, S. (2007). Intercultural Competence: The Status and Future of a Controversial Concept. Journal for Language and Intercultural Communication, 7(4), 254-26. https:/ / doi.org/10.2167/laic285.0

Risager, K. (1998). Language teaching and the process of European integration. in:

Michael Byram and Michael Fleming eds Language Learning in Intercultural

Pennycook, A. (2007). Language, Localization, and the Real: Hip-Hop and the Global Spread of Authenticity. Journal of Language, Identity \& Education, 6:2, 101 115.

URL: http:/ / dx.doi.org/10.1080/15348450701341246 Perspective. Approaches through drama and ethnography. Cambridge: Cambridge University Press, 242-54.

Risager, K. (2007). Language and culture pedagogy. Clevedon Multilingual Matters.

Scollon, R., and Scollon, S.W. (2001). Discourse and intercultural communication. In D. Schiffrin, Tannen, D., and Hamilton, H. (Ed.), The handbook of discourse analysis (pp. 538-547). Oxford: Blackwell.

Seriwatana, P. \& Charoensukmongkol, P. (2021). Cultural Intelligence and Relationship Quality in the Cabin Crew Team: The Perception of Members Belonging to Cultural Minority Groups. Journal of Human Resources in Hospitality and Tourism, 20(2), 147-173. https://doi.org/10.1080/15332845. 2020.1821431

Sysoyev, P. V., \& Donelson, L. R. (2002). Teaching cultural identity through modern language: Discourse as a marker of an individual's cultural identity. Journal of Eurasian Research, 2(4). Retrieved from http://elibrary.ru/item.asp?id $=13443750$

Tomlison, B. et al. (2001). ELT courses for adults. ELT Journal, 55(1), 80-101.

Tochon, F. (2009). The Key to Global Understanding: World Languages Education Why Schools Need to Adapt. Review of Educational Research, 79(2), 650-681. https:/ / doi.org/10.3102/0034654308325898

Tomalin, B., \& Stempleski, S. (1993). Cultural awareness. Oxford: Oxford University Press.

Wei, Y. (2005). Integrating Chinese Culture with TEFL in Chinese Classroom. SinoUS English Teaching, 2(7), 55-58.

Zaid, M. (2011). Caught between Scylla and Charybdis: Teaching English in a Plethora of Dialects and Cultures. Paper presented at Rhizomes VI (11-12 February 2011), the University of Queensland, Brisbane, Australia.

Zhao, B. (2011). How to enhance culture teaching in English language classes? Theory and Practice in Language Studies, 1(7), 847-850. https://doi.org/ 10.4304/tpls.1.7.847-850. 